\title{
GERMINAÇÃO DE SEMENTES DE PAU-DE-ESPETO (Casearia gossypiosperma) EM DIFERENTES TEMPERATURAS
}

\author{
Ademir Kleber Morbeck de Oliveira ${ }^{1}$, Juliana Santos Souza ${ }^{2}$, Júnior Manoel Braga de Carvalho ${ }^{2}$, \\ Simone Alves de Souza ${ }^{2}$ \\ ${ }^{1}$ Universidade Anhanguera-Uniderp, Campus de Ciências Biológicas, Agrárias e da Saúde, Campo Grande, Mato Grosso do Sul, \\ Brasil-akmorbeck@hotmail.com \\ ${ }^{2}$ Universidade Anhanguera-Uniderp, Curso de Ciências Biológicas, Campo Grande, Mato Grosso do Sul, Brasil - \\ juliana.santossouza@hotmail.com; braga_junior@live.com; simone260693@hotmail.com \\ Recebido para publicação: 12/06/2012 - Aceito para publicação: 18/08/2014
}

\begin{abstract}
Resumo
Casearia gossypiosperma Briq., uma espécie arbórea pertencente à família Salicaceae, é utilizada na construção civil, arborização e paisagismo. Em virtude de sua importância econômico-ecológica e da escassez de informações sobre seu processo germinativo, o presente trabalho foi realizado com o objetivo de determinar as temperaturas mais adequadas para a germinação de sementes de pau-deespeto. As sementes utilizadas no experimento foram coletadas no Pantanal de Miranda, Mato Grosso do Sul, Brasil. Em seguida, elas foram submetidas a seis tratamentos, com temperaturas constantes de 20, 25, 30 e $35{ }^{\circ} \mathrm{C}$ e alternadas de 20-30 e 25-35 ${ }^{\circ} \mathrm{C}$, em câmaras de germinação. Os resultados obtidos evidenciaram maior porcentagem de germinação das sementes nas temperaturas de 25 e $30{ }^{\circ} \mathrm{C}$, atingindo 83 e $84 \%$, maior velocidade de germinação $\left(10,0\right.$ em $25{ }^{\circ} \mathrm{C}$ e 10,7 em $\left.30{ }^{\circ} \mathrm{C}\right)$ e comprimento de plântula $\left(10,3 \mathrm{~mm}\right.$ em $25^{\circ} \mathrm{C}$ e $10,8 \mathrm{~mm}$ em $\left.30^{\circ} \mathrm{C}\right)$. Portanto, a faixa de temperatura ótima para a germinação de sementes de pau-de-espeto está entre 25 e $30^{\circ} \mathrm{C}$.

Palavras-chave: Pantanal; sementes florestais; formação de plântulas; Salicaceae.
\end{abstract}

\begin{abstract}
Germination of Casearia gossypiosperma seeds at different temperatures. The species Casearia gossypiosperma is a tree, Salicaceae family, and its wood is suitable for civil construction, afforest, and landscaping. Due to its economic potential, ecological importance, and lack of information on its germination process, the aim of this research was to evaluate seed germination at different temperatures. The seeds used were collected from Pantanal de Miranda, Mato Grosso do Sul - Brazil and were submitted to six different temperatures, constant of $20,25,30$ and $35^{\circ} \mathrm{C}$ and alternating, 20-30 and 25$35^{\circ} \mathrm{C}$, in germination chambers. The results revealed that most seeds germinated at 25 and $30{ }^{\circ} \mathrm{C}$, producing 83 and $84 \%$ of germination, higher germination speed $\left(10,0\right.$ at $25^{\circ} \mathrm{C}$ and 10.7 at $\left.30^{\circ} \mathrm{C}\right)$, and the greatest seedlings $\left(10.3 \mathrm{~mm}\right.$ at $25^{\circ} \mathrm{C}$ and $10.8 \mathrm{~mm}$ at $\left.30^{\circ} \mathrm{C}\right)$. Therefore, the best temperatures to germination are between 25 and $30^{\circ} \mathrm{C}$.

Keywords: Pantanal; forest seeds; seedlings formation; Salicaceae.
\end{abstract}

\section{INTRODUÇÃO}

Casearia gossypiosperma Briq. pertence à família Salicaceae. Popularmente conhecida como pau-de-espeto, cambroé ou espeteiro, é uma espécie arbórea (10-40 metros de altura), decídua e heliófila que se desenvolve no interior da floresta primária densa e em formações secundárias tardias nas regiões Norte (PA, AM, AC, RO), Nordeste (BA), Centro-Oeste (MT, GO, MS), Sudeste (MG, SP, RJ) e Sul (PR). A madeira de pau-de-espeto é moderadamente pesada, dura, quebradiça e resistente ao ataque de organismos xilófagos, sendo utilizada, principalmente, na construção civil e na ornamentação (SOARESSILVA; SILVA, 2000; LORENZI, 2008; KELLER et al., 2009).

A espécie pau-de-espeto também possui utilização medicinal, pois suas folhas apresentam princípios ativos antidiarreicos, antiofídicos, antirreumáticos, diuréticos e anti-inflamatórios (SIMÕES et al., 1986; LOPES, 1997; BORGES et al., 2001). Devido à sua importância, foi listada como prioritária

FLORESTA, Curitiba, PR, v. 45, n. 1, p. 97 -106, jan. / mar. 2015.

Oliveira, A. K. M. de. et al.

ISSN eletrônico 1982-4688 / ISSN impresso 0015-3826 
para conservação e manejo sustentável (VIEIRA et al., 2002), porém é uma espécie ainda com poucas informações sobre seu processo germinativo e crescimento inicial.

A germinação das sementes é um processo que envolve um conjunto de eventos físiológicos no embrião, que se inicia com a embebição e culmina com a protrusão da raiz primária dos envoltórios da semente (CASTRO; HILHORST, 2004). Para que esse processo ocorra, são necessárias condições adequadas, como luz, temperatura e água, que são importantes fatores ambientais controladores de germinação, tendo um papel crucial na regulação do crescimento e desenvolvimento das plantas (FENNER, 2000; BASKIN; BASKIN, 2001; BRASIL, 2009).

A temperatura determina a taxa de germinação, com a temperatura ótima propiciando uma porcentagem máxima em menor espaço de tempo, enquanto que temperaturas máximas e mínimas resultam em pequenas porcentagens de germinação ou a morte do embrião (CARVALHO; NAKAGAWA, 2012).

A temperatura, além de influenciar a germinação, também afeta o desenvolvimento inicial das plântulas, uma fase crítica do ciclo de vida, pois estas não possuem a habilidade que as sementes têm de suportar as condições adversas do ambiente e nem possuem a robustez física adquirida com a idade. Esse período envolve uma série de transformações que dependem de condições ambientais favoráveis, levando a altas taxas de mortalidade nesse estágio de desenvolvimento (KITAJIMA; FENNER, 2000; LARCHER, 2003; NUÑES; AZÓCAR, 2004).

Em virtude de sua importância econômico-ecológica e da escassez de informações a respeito de seu processo germinativo, o presente trabalho foi realizado com o objetivo de determinar as temperaturas mais adequadas para a germinação de sementes de pau-de-espeto (Casearia gossypiosperma Briq.).

\section{MATERIAL E MÉTODOS}

Em outubro de 2011, as sementes de Casearia gossypiosperma foram colhidas, com auxílio de podão, de 16 árvores localizadas em áreas de matas da Fazenda Baia Grande ( $\mathrm{S} 20.40877^{\circ} \mathrm{W} 056.34189^{\circ}$, elevação $150 \mathrm{~m}$ ), na região pantaneira do município de Miranda, Mato Grosso do Sul, Brasil. Posteriormente, elas foram acondicionadas em sacos de papel e transportadas para o Laboratório de Pesquisa em Sistemas Ambientais e Biodiversidade da Universidade Anhanguera-Uniderp, Campo Grande, MS, Brasil.

$\mathrm{O}$ teste de umidade das sementes foi realizado de acordo com o método de estufa a $105^{\circ} \mathrm{C} \pm 3$ por 24 horas (BRASIL, 2009), utilizando-se quatro lotes de cinquenta sementes cada. As sementes utilizadas para o teste de germinação sofreram assepsia superficial por imersão em hipoclorito de sódio (2\%) por três minutos, sendo, em seguida, lavadas em água corrente por um minuto.

Para a avaliação do efeito da temperatura sobre a germinação, utilizaram-se quatro repetições de 25 sementes colocadas em caixas de plástico transparente $(11 \times 11 \times 3,5 \mathrm{~cm})$, sobre duas folhas de papel germitest. De acordo com Brasil (2009), o papel foi previamente umedecido com 2,5 vezes o peso do substrato, utilizando-se uma solução aquosa de fungicida de contato do grupo químico das hidantoínas a $0,1 \%(\mathrm{~m} / \mathrm{v})$. As caixas foram mantidas em câmaras de germinação tipo B.O.D. (demanda biológica de oxigênio), nas temperaturas constantes de $20,25,30$ e $35{ }^{\circ} \mathrm{C}$ e alternadas de $20-30$ e $25-35{ }^{\circ} \mathrm{C}$, com fotoperíodo de $12 \mathrm{~h}$ de luz branca. Não foram encontradas citações na bibliografia consultada (LORENZI, 2008) sobre sensibilidade a luminosidade ou dormência das sementes da espécie, motivo pelo qual não foram aplicados tratamentos prévios.

A avaliação da germinação foi diária, sendo iniciada no primeiro dia após a instalação do teste e encerrada no $35^{\circ}$ dia, com as sementes consideradas germinadas quando apresentaram protrusão de raiz primária de, no mínimo, $2 \mathrm{~mm}$ de comprimento. Nas sementes não germinadas, seguindo procedimentos de Brasil (2009), realizou-se o teste de viabilidade de tetrazólio (sal trifenil-cloreto de tetrazólio a 1\% em solução aquosa). As sementes foram acondicionadas em caixas de plástico escuras, colocadas entre duas folhas de papel toalha umedecidas, em temperatura de $25^{\circ} \mathrm{C}$ por um período de 24 horas, com a solução. Após esse período de embebição, as sementes sofreram um corte longitudinal, ficando com o embrião exposto e possibilitando a visualização da coloração através de estereomicroscópio.

Para determinar a média de comprimento das raízes primárias e plântulas (BENINCASA, 2003), foram utilizados todos os indivíduos provenientes dos testes de germinação após o término do experimento (35 dias), medidos em milímetros, com auxílio de paquímetro digital. De acordo com Brasil 
(2009), foram consideradas plântulas normais as que apresentaram as estruturas essenciais da parte aérea e raiz primária, e plântulas anormais aquelas que desenvolveram estruturas defeituosas, tais como raízes atrofiadas ou ausência de raiz primária e/ou parte aérea.

Foram avaliadas a porcentagem de germinação, de acordo com a fórmula $\% \mathrm{G}=\left(\sum\right.$ ni. $\left.\mathrm{N}^{-1}\right) \cdot 100$ (FERREIRA; BORGHETTI, 2004) e o vigor, medido indiretamente pelo tempo médio de germinação em dias (TMG), quantificando a germinação sob o ponto de vista cinético, $\mathrm{t}=\sum \mathrm{n}_{\mathrm{i}} \mathrm{t}_{\mathrm{i}} / \mathrm{Sn}_{\mathrm{i}}(\mathrm{LABOURIAU}$; AGUDO, 1987) e pelo índice de velocidade de germinação (IVG $=G_{1} / N_{1}+G_{2} / N_{2}+\ldots G_{n} / N_{n}$ ) (MAGUIRE, 1962). Não houve necessidade de transformações dos dados de germinação, IVG e TMG, de acordo com os testes de normalidade e homogeneidade de variâncias.

O delineamento experimental foi o inteiramente casualizado, com dados tabulados e submetidos à análise de variância, com aplicação de regressão polinomial para as temperaturas constantes e comparação de médias pelo teste de Tukey (5\%), para temperaturas constantes e alternadas. O valor da temperatura ideal, utilizando os valores das temperaturas constantes, foi obtido através de uma adaptação da fórmula de Bhaskara, tendo sido montada uma série de equações que permitiram avaliar o ponto ideal de temperatura para a germinação das sementes da espécie.

\section{RESULTADOS E DISCUSSÃO}

$\mathrm{O}$ teor de água encontrado em sementes recém-colhidas foi de $3 \%$, um pouco abaixo do encontrado para a maioria das espécies vegetais, entre 5 e 20\% (BEWLEY; BLACK, 1994), porém diferente dos resultados encontrados por Imatomi et al. (2009) trabalhando com uma espécie do mesmo gênero (C. sylvestris Swartz), que variaram entre 14,5 e 22,9\% para sementes não armazenadas, com sementes procedentes de São Paulo e Paraná, e de 7,1 a 9,9\% para sementes armazenadas, lotes do estado do Paraná e São Paulo, respectivamente.

Rosa e Ferreira (2001) verificaram valores similares aos encontrados por Imatomi et al. (2009), de 9,5\% para a mesma espécie (C. sylvestris). Apesar do baixo teor de água nas sementes (3\%), este não foi um fator que interferiu negativamente no processo germinativo, nas condições testadas, levando-se em consideração as porcentagens de germinação obtidas nas temperaturas mais eficazes, acima de $80 \%$.

A germinação ocorreu a partir do terceiro dia na temperatura de $25^{\circ} \mathrm{C}$, estendendo-se até o $34^{\circ}$ dia (31 dias de germinação acumulada); na temperatura de 30 e $35^{\circ} \mathrm{C}$, ocorreu no quarto dia, sendo que na de $30^{\circ} \mathrm{C}$ estendeu-se até o $31^{\circ}$ dia ( 27 dias) e na de $35^{\circ} \mathrm{C}$ até o $22^{\circ}$ dia (18 dias); na faixa de $20-30^{\circ} \mathrm{C}$, ocorreu no sexto dia, estendendo-se até o $34^{\circ}$ dia (29 dias); na faixa de $25-35^{\circ} \mathrm{C}$, ocorreu no sétimo dia, estendendo-se até o $30^{\circ}$ dia ( 24 dias); e na temperatura de $20^{\circ} \mathrm{C}$, ocorreu no sétimo dia, estendendo-se até o $34^{\circ}$ dia (27 dias), com a emissão da raiz primária concentrando-se entre o sexto e décimo oitavo dia (Figura 1).

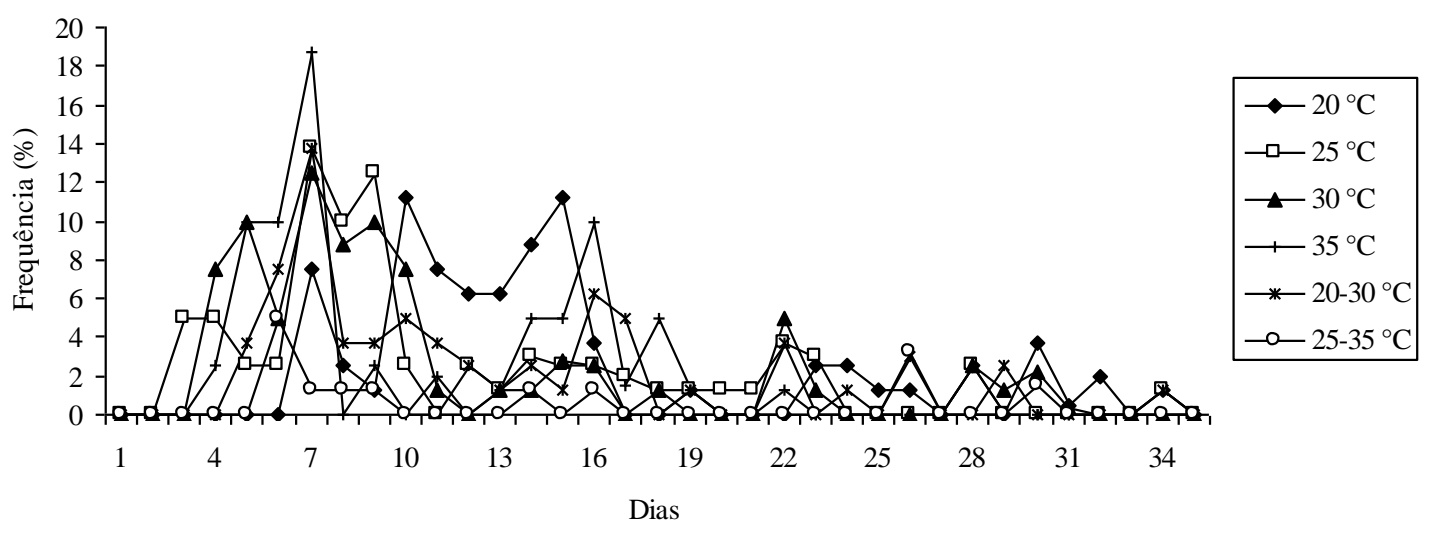

Figura 1. Frequência de germinação (\%) de sementes de Casearia gossypiosperma em quatro temperaturas constantes e duas alternadas, em B.O.D., com fotoperíodo de 12 horas.

Figure 1. Germination frequency (\%) of Casearia gossypiosperma seeds at four constant temperatures and two alternating temperatures in B.O.D. with photoperiod of 12 hours.

FLORESTA, Curitiba, PR, v. 45, n. 1, p. 97 -106, jan. / mar. 2015.

Oliveira, A. K. M. de. et al.

ISSN eletrônico 1982-4688 / ISSN impresso 0015-3826

99

DOI: $10.5380 /$ rf.v45i1.27599 
Pode-se observar que a espécie possui um período longo de germinação, mas a distribuição do processo germinativo durante vários dias pode ser um fator positivo, pois, de acordo com Brancalion e Marcos Filho (2008), pode permitir maior chance de as plântulas encontrarem um ambiente favorável a sua instalação. Levando-se em conta que a coleta de sementes foi realizada em outubro, considerado o final da estação de seca, período em que as primeiras chuvas são irregulares (BRASIL, 1982), a distribuição da germinação por várias semanas poderia ser uma adaptação a essa situação climática em que a precipitação é desigual.

Rosa e Ferreira (2001), utilizando sementes de C. sylvestris em substrato ágar e areia $\left(25^{\circ} \mathrm{C}\right)$, encontraram início de germinação entre o $12^{\circ}$ e o $21^{\circ}$ dia, e o final entre o $33^{\circ}$ e o $45^{\circ}$ dia, indicando que esse gênero pode distribuir sua germinação por um período longo de tempo. Imatomi et al. (2009) indicaram o início da emergência, em casa de vegetação, entre 24 e 28 dias pós-semeadura para C. sylvestris. Já Lorenzi (2008) constatou que a emergência de $C$. gossypiosperma em substrato organoargiloso demora entre 15 e 30 dias, em canteiro sombreado.

Os resultados encontrados nesta pesquisa indicaram que essa espécie pode possuir comportamento germinativo distinto, germinando mais rapidamente (Figura 1) dependendo da região da coleta e levando em consideração as diferenças nos tratamentos testados (câmara de germinação e canteiro), mas também com a característica de distribuir sua germinação por várias semanas (Figura 1), comportamento similar aos citados pelos autores Rosa e Ferreira (2001), Lorenzi (2008) e Imatomi et al. (2009).

Os valores finais de germinação entre as temperaturas constantes indicaram que 20,25 e $30^{\circ} \mathrm{C}$ foram as mais adequadas, estatisticamente iguais $(\mathrm{F}=46.3750, \mathrm{p}<0.0001)$, com valores entre 83 e $85 \%$ (Tabela 1). O ponto da temperatura ideal para germinação foi obtido em $29{ }^{\circ} \mathrm{C}$ (Figura 2), que se situa entre os melhores valores obtidos para germinação, IVG e TMG, além da formação de plântulas normais, entre 25 e $30^{\circ} \mathrm{C}$, indicando sua adequação à espécie. A curva de regressão obtida, que permitiu encontrar a temperatura ótima, apresentou uma alta qualidade, $\operatorname{com} \mathrm{R}^{2}=1$, pois quanto mais próximo a 1,0 , menor a dispersão dos valores avaliados.

A temperatura de $35^{\circ} \mathrm{C}$ foi a que apresentou a menor taxa de germinação em relação às temperaturas constantes. De acordo com Bewley e Black (1994), a temperatura é importante no processo de germinação e, quando elevadas, podem provocar diminuição do suprimento de aminoácidos livres, da síntese proteica e de reações anabólicas, afetando negativamente o processo de germinação, embora sem afetar o vigor de germinação (Tabela 1).

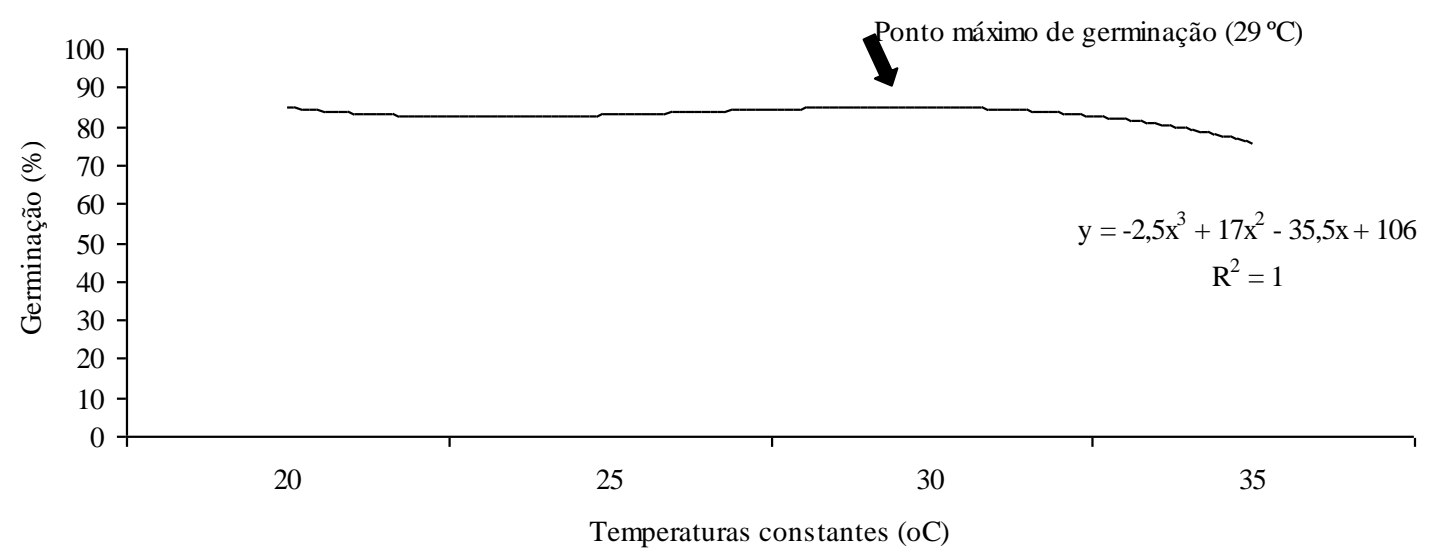

Figura 2. Germinação (\%) de sementes de Casearia gossypiosperma em quatro temperaturas constantes. Figure 2. Germination (\%) of Casearia gossypiosperma seeds in four constant temperature.

Comparando-se os resultados das temperaturas constantes com as alternadas (Tabela 1), observase que a temperatura alternada de $25-35{ }^{\circ} \mathrm{C}$ foi a que apresentou o pior resultado, com $16 \%$ de germinação, indicando sua inadequação à espécie, com resultados estatisticamente diferentes das demais temperaturas $(\mathrm{F}=915.5591, \mathrm{p}<0.0001)$. 
Os resultados apresentados por Davide et al. (1995), com espécie do mesmo gênero (C. lasiophylla Eichl.), indicaram germinação entre 30 e 70\%, com sementes sem tratamento, resultados similares aos encontrados neste trabalho. Já Rosa e Ferreira (2001), com a espécie C. sylvestris, encontraram valores entre 0 e $47 \%$ de germinação $\left(35\right.$ e $25^{\circ} \mathrm{C}$, respectivamente, substrato ágar e areia), similares aos citados por Imatomi et al. (2009), entre 0 e menos de $40 \%\left(33\right.$ e $30^{\circ} \mathrm{C}$, respectivamente, em casa de vegetação), abaixo dos encontrados para C. gossypiosperma.

As diferenças de resultados podem estar relacionadas ao período de coleta, origem das sementes ou mesmo a características da própria espécie, uma vez que $C$. gossypiosperma pode possuir como padrão a produção e germinação de uma grande quantidade de sementes. Essas características são comuns em espécies consideradas pioneiras, com grande produção de sementes e dispersão anemocórica (AGUIAR $e t$ al., 1993), o que parece ser a característica de C. gossypiosperma, embora não tenham sido encontradas referências sobre a classificação ecológica da mesma.

Em relação ao vigor de sementes (Tabela 1), medido indiretamente por IVG e TMG, as temperaturas de 25,30 e $35^{\circ} \mathrm{C}$ resultaram em maiores valores de IVG e menor TMG, indicando serem as temperaturas mais adequadas para a obtenção de maior vigor de germinação.

Tabela 1. Germinação, índice de velocidade de germinação (IVG), tempo médio de germinação (TMG) e resultados da análise de variância de sementes de Casearia gossypiosperma submetidas a diferentes temperaturas.

Table 1. Germination, speed germination index (SGI), average germination time (MGT) and results of analyzes of variance of Casearia gossypiosperma seeds submitted to different temperatures.

\begin{tabular}{lccc}
\hline Temperatura $\left({ }^{\circ} \mathbf{C}\right)$ & Germinação $(\%)$ & IVG & TMG (dias) \\
\hline 20 & $85 \mathrm{a}$ & $6,6 \mathrm{c}$ & $15,2 \mathrm{~d}$ \\
25 & $83 \mathrm{a}$ & $10 \mathrm{a}$ & $11 \mathrm{a}$ \\
30 & $85 \mathrm{a}$ & $10,7 \mathrm{a}$ & $10,8 \mathrm{a}$ \\
35 & $76 \mathrm{~b}$ & $9,3 \mathrm{ab}$ & $10,3 \mathrm{a}$ \\
$20-30$ & $73 \mathrm{~b}$ & $7,5 \mathrm{bc}$ & $12,7 \mathrm{~b}$ \\
$25-35$ & $16 \mathrm{c}$ & $1,6 \mathrm{~d}$ & $14,2 \mathrm{c}$ \\
\hline Fontes de variação & GL & SQ & QM \\
\hline \multicolumn{5}{c}{ Germinação $(\%)$} \\
\hline Tratamentos & 5 & $14.2 \mathrm{e}+03$ & $28.4 \mathrm{e}+02$ \\
Erro & 18 & 82.000 & 4.556 \\
\hline \multicolumn{5}{c}{ IVG } \\
\hline Tratamentos & 5 & 230.212 & 46.042 \\
Erro & 18 & 19.777 & 1.099 \\
\hline \multicolumn{5}{r}{} \\
\hline Tratamentos & 5 & 80.373 & 16.075 \\
Erro & 18 & 2.740 & 0.152 \\
Médias seguidas pela mesma letra na coluna não diferem estatisticamente entre si pelo teste de Tukey $(\mathrm{p}>0,05)$.
\end{tabular}

Apesar de a temperatura de $20{ }^{\circ} \mathrm{C}$ ter propiciado uma boa taxa de germinação e raízes primárias com tamanho estatisticamente iguais à temperatura de $25^{\circ} \mathrm{C}$ (Tabelas 1 e 2), o vigor de germinação foi prejudicado, com as sementes distribuindo sua germinação por um período maior de tempo, o que significou menor IVG e maior TMG. Também o tamanho final das plântulas foi menor, quando comparado a $25{ }^{\circ} \mathrm{C}$ (Tabela 2). Do mesmo modo a temperatura alternada de $25-35^{\circ} \mathrm{C}$ apresentou efeito negativo sobre o vigor, prolongando o tempo de germinação, com resultados estatisticamente inferiores aos dos demais tratamentos (IVG: $\mathrm{F}=44.2605$, $\mathrm{p}<0.0001$; TMG: $\mathrm{F}=52.2906, \mathrm{p}<0.0001$ ).

De acordo com Marcos Filho (2005) e Taiz e Zeiger (2009), as temperaturas abaixo do ponto ótimo provocam atraso na germinação, devido à redução da atividade das enzimas relacionadas à respiração e do metabolismo celular.

Já nas temperaturas de 25 e $30{ }^{\circ} \mathrm{C}$, as sementes germinaram em menor tempo e em maior quantidade (maior IVG e menor TMG), além de produzirem plântulas e raízes primárias maiores, resultados similares aos descritos por Silva et al. (2008) com Erythroxylum ligustrinum DC. 
(Erythroxylaceae), em que a faixa de temperatura de 25 e $30^{\circ} \mathrm{C}$ foi considerada ideal para germinação e apresentou maior IVG, corroborando informações de Aguiar et al. (1993), que informam que as sementes de diversas espécies florestais subtropicais e tropicais têm maior potencial de germinação na faixa de temperatura entre 20 e $30^{\circ} \mathrm{C}$. Por outro lado, com família da mesma ordem (Malpighiales Mart. (1835)), em trabalho com sementes de Heteropteris aphrodisiaca O. Mach., família Malpighiaceae, Silva et al. (2006) apresentaram resultados distintos aos obtidos neste trabalho, sem diferenças entre a germinação e formação de plântulas a 30 ou $25-30^{\circ} \mathrm{C}$, sendo as duas adequadas para a espécie.

Resultado similar também foi obtido por Barbosa et al. (2008), com sementes de achachairu (Garcinia sp. - Clusiaceae, ordem Malpighiales), em que as temperaturas de 25,30 e $20-30{ }^{\circ} \mathrm{C}$ foram as mais adequadas para a germinação, e para maior IVG, $30^{\circ} \mathrm{C}$. Esses resultados são parcialmente similares ao obtido neste trabalho, com o maior IVG sendo alcançado nas temperaturas de 25,30 e $35^{\circ} \mathrm{C}$.

A temperatura de $35^{\circ} \mathrm{C}$, apesar de propiciar IVG e TMG estatisticamente iguais a 25 e $30^{\circ} \mathrm{C}$ (IVG: $\mathrm{F}=8.6672, \mathrm{p}<0.0001$; TMG: $\mathrm{F}=95.7984, \mathrm{p}<0.0001$ ), afetou negativamente o desenvolvimento das plântulas, com as mesmas não possuindo as estruturas necessárias para sua sobrevivência. Mesmo em um período de 12 horas $\left(25-35^{\circ} \mathrm{C}\right)$, não é recomendado para as sementes da espécie, pois também não gerou plântulas normais. Da mesma maneira, a temperatura alternada de $20-30{ }^{\circ} \mathrm{C}$ não é adequada, gerando menor taxa de germinação e plântulas pouco desenvolvidas (Tabela 2).

Imatomi et al. (2009), com sementes de $C$. sylvestris, verificaram que, em relação à velocidade de germinação, as temperaturas 27,30 e $20-30{ }^{\circ} \mathrm{C}$ não apresentaram diferenças entre si, resultado diferente em relação à temperatura de $20-30{ }^{\circ} \mathrm{C}$ utilizada para $C$. gossypiosperma, que aumentou o tempo de germinação.

Em relação à formação de plântulas normais (parte aérea + raiz primária) (Tabela 2), as temperaturas de 25 e $30{ }^{\circ} \mathrm{C}$ foram as que propiciaram o maior número, enquanto $35{ }^{\circ} \mathrm{C}$ e $25-35{ }^{\circ} \mathrm{C}$ não permitiram a formação de plântulas normais, provavelmente devido à alta temperatura, que pode ter consumido as reservas das sementes logo após a germinação, podendo ter levado à morte das mesmas.

Nas temperaturas de $20{ }^{\circ} \mathrm{C}$ e $20-30{ }^{\circ} \mathrm{C}$, ocorreu uma menor formação de plântulas normais, indicando também sua inadequação para a espécie. Levando em consideração que temperaturas mais baixas podem afetar negativamente os processos metabólicos, dependendo da espécie, um maior espaço de tempo poderia ser necessário para a formação das plântulas, o que é confirmado por Bewley e Black (1994) e Taiz e Zeiger (2009), assegurando que a temperatura pode influir no processo de crescimento, especialmente alterando a velocidade de absorção de água e modificando a velocidade das reações químicas, o que afeta a ressíntese de substâncias para a plântula e atrasa o seu crescimento.

Estatisticamente, o número de plântulas normais (Tabela 2) foi significativamente maior $(\mathrm{F}=1732, \mathrm{p}<0.0001)$ nas temperaturas de 25 e $30^{\circ} \mathrm{C}$, que também produziram plântulas de maior tamanho, estatisticamente diferentes dos demais tratamentos $(\mathrm{F}=14.50, \mathrm{p}<0.0001)$. Já o maior comprimento das raízes primárias foi obtido nas temperaturas de 20 e $25{ }^{\circ} \mathrm{C}$, estatisticamente superiores às demais $(\mathrm{F}=115.3429, \mathrm{p}<0.0001)$.

Para Champagnat (1992), as baixas temperaturas são responsáveis pelo aumento dos níveis endógenos de giberelinas nas plantas, um regulador de crescimento, o que poderia levar a um maior crescimento das raízes. Porém o efeito da temperatura sobre o crescimento do sistema radicular pode ser variável, de acordo com a espécie. Pereira et al. (2001), trabalhando com Malus prunifolia Borkh. cv. Marubakaido, verificaram uma diminuição do sistema radicular, enquanto Arnould e Young (1990), com Malus x domestica 'Delicious', constataram crescimento da raiz, todos utilizando baixas temperaturas.

De acordo com Cassaro-Silva (2001), trabalhando com a entalpia na germinação das sementes de Senna macranthera (Collad.) Irwin et Barn. (Fabaceae), em temperaturas supraótimas ou muito elevadas em relação àquelas que a espécie tolera, a energia contida nas células ou sistemas de membranas celulares da semente fica cada vez menos favorável ao crescimento do embrião, até atingir a temperatura máxima em que toda a energia é dissipada e, como consequência, todos os processos mediados por enzimas são interrompidos, levando à morte do embrião. Dessa maneira, poderia ocorrer a protrusão da raiz primária, mas o embrião não teria mais energia para continuar o processo de crescimento, levando à morte da plântula, o que talvez tenha ocorrido na temperatura de $35^{\circ} \mathrm{C}$ (Tabela 2), temperatura em que várias sementes germinaram, mas não conseguiram formar raízes primárias completas ou a parte aérea. 
Tabela 2. Comprimento da raiz primária $(\mathrm{mm})$, tamanho total da plântula $(\mathrm{mm})$, porcentagem de plântulas normais (formação de parte aérea e raiz primária) e sementes mortas de Casearia gossypiosperma em seis diferentes temperaturas.

Table 2. Average length primary root and seedlings $(\mathrm{mm})$ and normal seedlings (\%) (primary root and aerial part) of Casearia gossypiosperma at six different temperatures.

\begin{tabular}{lcccc}
\hline Temperatura $\left({ }^{\circ} \mathbf{C}\right)$ & Raiz primária $(\mathbf{m m})$ & Plântulas $(\mathbf{m m})$ & Plântulas normais (\%) & Sementes mortas \\
\hline 20 & $3,0 \mathrm{a}$ & $7,9 \mathrm{~b}$ & $22 \mathrm{~b}$ & $14 \mathrm{a}$ \\
25 & $3,2 \mathrm{a}$ & $10,3 \mathrm{a}$ & $52 \mathrm{a}$ & $15 \mathrm{a}$ \\
30 & $2,6 \mathrm{~b}$ & $10,8 \mathrm{a}$ & $52 \mathrm{a}$ & $16 \mathrm{a}$ \\
35 & $0 \mathrm{c}$ & $0 \mathrm{c}$ & $0 \mathrm{c}$ & $27 \mathrm{~b}$ \\
$20-30$ & $1,9 \mathrm{~b}$ & $7,5 \mathrm{~b}$ & $20 \mathrm{~b}$ & $25 \mathrm{~b}$ \\
$25-35$ & $2 \mathrm{~b}$ & $0 \mathrm{c}$ & $0 \mathrm{c}$ & $81 \mathrm{c}$ \\
\hline
\end{tabular}

Também Labouriau e Labouriau (1997) mencionam que a desnaturação de proteínas e a transição de fase das membranas celulares, além da limitação do processo respiratório, restrito pela difusão dos gases e lenta em relação à velocidade das reações respiratórias, poderiam estar entre os fatores limitantes da germinação e crescimento inicial, o que talvez tenha acontecido na temperatura de $35^{\circ} \mathrm{C}$ (Tabela 2), na qual as plântulas não conseguiram se desenvolver.

Pode-se supor que em temperaturas mais elevadas a atividade respiratória tenha se sobressaído em relação aos demais processos fisiológicos e este fator tenha esgotado as reservas das sementes, levando a uma menor germinação, plântulas de menor massa ou mesmo a sua morte, o que, de acordo com Taiz e Zeiger (2009), é causado pelo aumento de temperatura, que determina a velocidade das reações enzimáticas, afetando as taxas respiratórias.

Carneiro e Aguiar (1993) afirmam que, quando ocorre aumento da taxa de respiração, esgotamse rapidamente as substâncias de reserva da semente, das quais ela depende para germinar, além de facilitar o crescimento inicial da plântula. Amarante et al. (2007) confirmam essa probabilidade em trabalho com sementes de Araucaria angustifolia (Bertoloni) Otto Kuntze (Araucariaceae) em diferentes temperaturas, no qual verificaram um aumento da taxa respiratória até $40{ }^{\circ} \mathrm{C}$, indicando o efeito do aumento de temperatura na germinação no consumo das reservas das sementes.

Avaliando-se a porcentagem de sementes mortas através do teste do tetrazólio, foi observado que as sementes não germinadas já não eram mais viáveis (Tabela 2). A maior porcentagem de sementes mortas ocorreu na temperatura de $25-35^{\circ} \mathrm{C}$, indicando que a alternância de temperatura, associada a uma temperatura mais elevada $\left(35^{\circ} \mathrm{C}\right)$ não é adequada, fator também observado em $35{ }^{\circ} \mathrm{C}$, talvez pelo consumo das reservas, tal como mencionado por Amarante et al. (2007). A temperatura alternada de 20$30{ }^{\circ} \mathrm{C}$ também causou a morte de parte dos embriões, com valores estatisticamente significativos $(\mathrm{F}=767.5636, \mathrm{p}<0.0001)$, indicando que essa alternância não é adequada, nas condições testadas. As sementes não germinadas, nas demais temperaturas $\left(20,25\right.$ e $\left.30^{\circ} \mathrm{C}\right)$, também não eram mais viáveis, indicando que a espécie, na região de estudo, pode produzir uma certa quantidade de sementes que não irão germinar, fator compensado pela grande produção de sementes por árvore, conforme citado por Lorenzi (2008) e observado em campo.

Avaliando-se todos os parâmetros, as temperaturas mais adequadas para a germinação das sementes e formação de plântulas são 25 e $30{ }^{\circ} \mathrm{C}$, estatisticamente diferentes das demais temperaturas testadas (Tabela 2). Brancalion et al. (2010) também afirmaram que a temperatura de $25{ }^{\circ} \mathrm{C}$ é a mais adequada para a condução de teste de germinação com espécies do bioma Cerrado.

\section{CONCLUSÃO}

- Os dados obtidos indicam que a temperatura ótima para a germinação de sementes de pau-de-espeto é de $29^{\circ} \mathrm{C}$, obtida através de uma curva de regressão, que apresentou uma alta qualidade $\left(\mathrm{R}^{2}=1\right)$, com pequena dispersão dos dados avaliados. Essa temperatura também é adequada para a formação de plântulas normais e de maior tamanho, embora a espécie germine em uma ampla faixa de temperatura. Levando-se em consideração germinação, vigor e formação de plântulas normais, entre as temperaturas testadas, $25^{\circ} \mathrm{C}$ se destacou. 


\section{AGRADECIMENTOS}

Os autores agradecem à Universidade Anhanguera-Uniderp, pelo financiamento do projeto GIP (Grupo Interdisciplinar de Pesquisa) e pela bolsa concedida (PIC), e ao Conselho Nacional de Desenvolvimento Científico e Tecnológico (CNPq), pelas bolsas de Iniciação Científica (PIBIC) e de Produtividade em Pesquisa concedidas. Também agradecem ao matemático Reginaldo Acylino de Moura Rodrigues, pela adaptação da fórmula de Bhaskara, e aos consultores, pelas críticas e sugestões apresentadas ao artigo.

\section{REFERÊNCIAS}

AGUiAR, I. B.; PIÑA-RODRIGUES, F. C. M.; FIGLIOLIA, M. B. Sementes Florestais Tropicais. Jaboticabal: FUNEP, 1993. 588 p.

AMARANTE, C. V. T.; MOTA, C. S.; MEGGUER, C. A.; IDE, G. M. Conservação pós-colheita de pinhões [sementes de Araucaria angustifolia (Bertoloni) Otto Kuntze] armazenados em diferentes temperaturas. Ciência Rural, Santa Maria, v. 37, n. 2, p. 346 - 351, 2007.

ARNOULD, M. A.; YOUNG, E. Growth and protein content of apple in response to root and shoot temperature following chilling. HortScience, Alexandria, v. 25, n. 12, p. 1583 - 1588, 1990.

BARBOSA, W.; ChAGAS, E. A.; MARTINS, L.; PIO, R.; TUCCI, M. L. S.; ARTIOLI, F. A. Germinação de sementes e desenvolvimento inicial de plântulas de achachairu. Revista Brasileira de Fruticultura, Jaboticabal, v. 30, n. 1, p. 263 - 266, 2008.

BASKIN, C. C.; BASKIN, J. M. Seeds: ecology, biogeography, and evolution of dormancy and germination. San Diego: Academic Press, 2001. 666 p.

BENINCASA, M. M. P. Análise de crescimento de plantas (noções básicas). Jaboticabal: FUNEP, 2003. $41 \mathrm{p}$.

BEWLEY, J. D.; BLACK, M. Seeds: physiology of development and germination. 2.ed. New York and London: Plenum Press, 1994. 445 p.

BORGES, M. H.; SOARES, A. M.; RODRIGUES, V. M.; OLIVEIRA, F.; FRANSHESCHI, A. M.; RUCAVADO, A.; GIGLIO, J. R.; HOMSI-BRANDEBURGO, M. I. Neutralization of proteases from Bothrops snake venoms by the aqueous extract from Casearia sylvestris (Flacourtiaceae). Toxicon, Oxford, v. 39, n. 12, p. 1863 - 1869, 2001.

BRANCALION, P. H. S.; MARCOS FILHO, J. Distribuição da germinação no tempo: causas e importância para a sobrevivência das plantas em ambientes naturais. Informativo ABRATES, Londrina, v. 18, n. 1, 2, 3, p. $11-17,2008$.

BRANCALION, P. H. S.; NOVEMBRE, A. D. L. C.; RODRIGUES, R. R. Temperatura ótima de germinação de sementes de espécies arbóreas brasileiras. Revista Brasileira de Sementes, Londrina, v. 32 , n. 4 , p. $15-21,2010$.

BRASIL. Ministério das Minas e Energia. Departamento Nacional de Produção Mineral. Projeto RADAMBRASIL. Folha SE. 21 Corumbá e parte da folha SE. 20: geologia, morfologia, pedologia, vegetação e uso potencial da terra. Rio de Janeiro; 1982. 448 p. (Levantamento de Recursos Naturais, 27).

BRASIL. Ministério da Agricultura, Pecuária e Abastecimento. Regras para análise de sementes. Brasília: Secretaria de Defesa Agropecuária. Mapa/ACS, 2009. 399 p.

CARNEIRO, J. G. A.; AGUIAR, I. B. Armazenamento de sementes. In: AGUIAR, I. B.; PIÑARODRIGUES, F. C. M.; FIGLIOLIA, M. B. Sementes Florestais Tropicais. Jaboticabal: FUNEP, 1993. p. $333-350$.

CARVALHO, N. M.; NAKAGAWA, J. Sementes: ciência, tecnologia e produção. 5. ed. Jaboticabal: FUNEP, 2012. $590 \mathrm{p}$. 
CASSARO-SILVA, M. Efeito da temperatura na germinação de sementes de manduirana (Senna macranthera (Collad.) Irwin et Barn. - Caesalpiniaceae). Revista Brasileira de Sementes, Brasília, v. 23, n. 1, p. 92 - 99, 2001.

CASTRO, R. D.; HILHORST, H. W. M. Embebição e reativação do metabolismo. In: FERREIRA, A. G.; BORGHETTI, F. (Eds.). Germinação: do básico ao aplicado. Porto Alegre: Artmed, 2004. p. 149 - 162.

CHAMPAGNAT, P. Dormance des bourgeons chez lês végétaux ligneux. In: CÔME, D. (Ed.). Les végétaux et le froid. Paris: Hermann, 1992. p. 203 - 260.

DAVIDE, A. C.; FARIA, J. M. R.; BOTELHO, S. A. Propagação de espécies florestais. Belo Horizonte: CEMIG/UFLA/FAEPE; Lavras: UFLA, 1995. 41p.

FENNER, M. Seeds: the ecology of regeneration in plant communities. 2nd. Wallingford: CABI Publishing, 2000. 410 p.

FERREIRA, A. G.; BORGHETTI, F. Germinação: do básico ao aplicado. Porto Alegre: Artmed, 2004. $323 \mathrm{p}$.

IMATOMI, M.; PEREZ, S. C. J. G. A.; FERREIRA, A. G. Caracterização e comportamento germinativo de sementes de Casearia sylvestris Swartz (SALICACEAE). Revista Brasileira de Sementes, v. 31. n. 2, p. $36-47,2009$.

KELLER, H. A.; GATTI, F. E.; HERRERA, J. Novedades en Casearia (Flacourtiaceae) para Argentina. Bonplandia, Corrientes, v. 18, n. 1, p. 13 - 17, 2009.

KITAJIMA, K.; FENNER, M. Ecology of seedling regeneration. In: FENNER, M. Seeds: the ecology of regeneration in plant communities. 2. ed. [S.1.]: CABI publishing, 2000. p. 331 - 359.

LABOURIAU, L. G.; AGUDO, M. On the physiology of seed germination in Salvia hispanica L. I Temperature effects. Anais da Academia Brasileira de Ciências, Rio de Janeiro, v. 59, n. 1, p. 37 - 50, 1987.

LABOURIAU, L. G.; LABOURIAU, I. S. Physiological rate processes from the point of view of absolute reaction rate theory. Ciência e Cultura Journal Brazilian Association for the Advancement of Science, São Paulo, v. 49, n. 3, p. 177 - 189, 1997.

LARCHER, W. Physiological plant ecology: ecophysiology and stress physiology of functional groups. $4^{\text {th }}$. Berlin: Springer, 2003. 533 p.

LOPES, A. M. V. Plantas usadas na medicina popular do Rio Grande do Sul. Santa Maria: INCOGRAPH, 1997. 49 p.

LORENZI, H. Árvores brasileiras: manual de identificação e cultivo de plantas arbóreas nativas do Brasil. 5 ed. v. 1. Nova Odessa: Instituto Plantarum, 2008. 384 p.

MAGUIRE, J. D. Speed of germination aid in selection and evaluation for seedling and vigour. Crop Science, Madison, v. 2, n. 176 - 177, 1962.

MARCOS FILHO, J. Fisiologia de sementes de plantas cultivadas. Piracicaba: FEALQ, 2005. 495 p.

NUÑES, C. G.; AZÓCAR, A. Ecología de la regeneración de árboles de la sabana. Ecotropicos, Merida, v. 17, n. 1, 2, p. 1 - 24, 2004.

PEREIRA, J. E. S.; FORTES, G. R. L.; SILVA, J. B. Efeito da aplicação de baixa temperatura em plantas de macieira sobre o crescimento durante a aclimatização. Pesquisa Agropecuária Brasileira, Brasília, v. 36, n. 1, p. 89 - 95, 2001.

ROSA, S. G. T.; FERREIRA, A. G. Germinação de sementes de plantas medicinais lenhosas. Acta Botanica Brasilica, São Paulo, v. 15, n. 2, p. 147 - 154, 2001.

SIMÕES, C. M. O.; MENTZ, L. A.; SCHENKEL, E. P.; IRGANG, B. E. Plantas da medicina popular no Rio Grande do Sul. Porto Alegre: FUFRGS, 1986. 173 p. 
SILVA, B. M. S.; CESARINO, F.; SAUDER, R.; LIMA, J. D. Germinação e armazenamento de sementes de coca (Erythroxylum ligustrinum DC. - Erythroxylaceae). Revista Brasileira de Sementes, Brasília, v. 30, n. 3, p. 25 - 29, 2008.

SILVA, P. S. R.; GUIMARÃES, S. C.; ALBUQUERQUE, M. C. F.; COELHO, M. F. B. Substrate and temperature regime on the germination of Heteropteris aphrodisiaca O. Mach. (Malpighiaceae) seeds. Revista Brasileira de Plantas Medicinais, Botucatu, v. 8, n. esp., p. 35 - 38, 2006.

SOARES-SILVA, L. H.; SILVA, F. C. Arboreal flora of the Godoy Forest State Park, Londrina, PR, Brazil. Edinburgh Journal of Botany, Edinburgh, v. 57, n. 1, p. 107 - 120, 2000.

TAIZ, L.; ZEIGER, E. Fisiologia vegetal. 4. ed. Porto Alegre: Artmed, 2009. 719 p.

VIEIRA, R. E.; SILVA, S. R.; ALVES, R. B. N.; SILVA, D. B.; WETZEL, M. M. V. S.; DIAS, T. A. B.; UDRY, M. C.; MARTINS, R. C. Estratégias para conservação e manejo de recursos genéticos de plantas medicinais e aromáticas: resultados da primeira reunião técnica. Brasília: Embrapa Recursos Genéticos e Biotecnologia; IBAMA; CNPq, 2002. 184 p. 